\title{
Tissue Inhibitor of Metalloproteinases 3 Regulates Resolution of Inflammation following Acute Lung
} Injury

\author{
Sean E. Gill, ${ }^{*}$ Isham Huizar, ${ }^{*}$ Eli M. Bench, ${ }^{*}$ \\ Samuel W. Sussman, ${ }^{*}$ Ying Wang, ${ }^{*}$ \\ Rama Khokha, ${ }^{\dagger}$ and William C. Parks ${ }^{*}$ \\ From the Center for Lung Biology, ${ }^{*}$ University of Washington, \\ Seattle, Washington; and the Ontario Cancer Institute, \\ University of Toronto, Toronto, Ontario, Canada
}

Tissue inhibitor of metalloproteinases 3 (TIMP3) inhibits not only matrix metalloproteinases but also a disintegrin and metalloproteinase domain family members and thus contributes to controlling diverse processes mediated by proteolysis. We used Timp $3^{-/-}$ mice to assess the role of this inhibitor in acute lung injury. After bleomycin-induced injury, inflammation, as indicated by the influx of neutrophils in bronchoalveolar lavage (BAL), peaked at 7 days post-injury in the wild-type mice and began to wane thereafter; however, in Timp $3^{-/-}$mice, inflammation persisted up to 28 days. Furthermore, although the level of chemokines in BAL and lung homogenate was similar in both genotypes, BAL from $\operatorname{Timp}^{-/-}$mice 7, 14, and 28 days post-injury had increased neutrophil chemotactic activity compared with wild-type BAL. At day 14, a higher percentage of apoptotic neutrophils were present in wild-type mice compared with $\operatorname{Timp}^{-/-}$ mice, further suggesting that TIMP3 constrains continued neutrophil influx. In addition, total matrix metalloproteinase activity was increased in lungs from Timp $3^{-1-}$ mice, and treatment of mice with a synthetic inhibitor of metalloproteinases rescued the enhanced neutrophilia phenotype. These data demonstrate that TIMP3 regulates neutrophil influx in the lung following injury through its ability to inhibit metalloproteinase activity and indicates that TIMP3 functions to promote the resolution of inflammation in the lung. (Am J Pathol 2010, 176:64-73; DOI: 10.2353/ajpath.2010.090158)

Acute lung injury, which often results from severe pulmonary infection or trauma and can progress to acute re- spiratory distress syndrome, is characterized by profound inflammation and tissue injury. ${ }^{1}$ Recovery from acute lung injury requires the proper regulation of wound repair, inflammation, and the deposition and remodeling of extracellular matrix. ${ }^{2}$ Many of these processes are mediated by matrix metalloproteinases (MMPs), which in turn are balanced by their natural inhibitors, the tissue inhibitors of metalloproteinases (TIMPs). ${ }^{2-4}$

TIMP3, which is expressed and stored in the lung matrix, is unique from other TIMPs in that in addition to inhibiting MMPs, it is also an efficient inhibitor of multiple members of the a disintegrin and metalloproteinase (ADAM) domain family, including ADAM17 or tumor necrosis factor $\alpha$ (TNF $\alpha$ )-converting enzyme. ${ }^{3}$ The importance of TIMP3 in lung homeostasis is highlighted by the development of enlarged alveolar spaces in aging TIMP3-null (Timp3 ${ }^{-1-}$ ) mice. ${ }^{5}$ Additionally, adult Timp3 ${ }^{-1-}$ mice have altered inflammatory responses in various tissues. For example, following partial hepatectomy or systemic LPS exposure, circulating levels of active TNF $\alpha$ are increased in Timp3 $3^{-1-}$ mice compared with wild-type mice. ${ }^{6,7}$ Furthermore, shedding of TNF $\alpha$ is increased in macrophages isolated from Timp3 $^{-1-}$ mice, ${ }^{7}$ suggesting that TIMP3 controls the proinflammatory activation of macrophages in a cell-autonomous manner.

Several members of both the MMP and TIMP families have been demonstrated to control various processes in response to lung injury. For example, our group and others demonstrated that mice lacking matrilysin (MMP7) are protected from bleomycin-induced lung injury due to impaired neutrophil migration into the air space during the acute phase and to a later modest reduction in fibrosis. ${ }^{8,9}$ Mice lacking TIMP1 reveal phenotypes in response

Supported by grants from the Canadian Institutes of Health Research, the Clayton F. Steward Endowed Research Fund, and the National Institutes of Health (HL29594, HL077555, and HL082658).

Accepted for publication September 22, 2009.

Supplemental material for this article can be found on http://ajp. amjpathol.org.

Address reprint requests to Sean E. Gill, Ph.D., Center for Lung Biology, University of Washington, 815 Mercer Street, Seattle, WA 98109. E-mail: segill@u.washington.edu. 
to bleomycin injury that are nearly opposite to those seen in $\mathrm{Mmp}^{-1-}$ mice, such as enhanced neutrophil influx into the alveolar space, ${ }^{10,11}$ likely due to its ability to inhibit MMP7. ${ }^{10,11}$ Overexpression of TIMP1 in the lung epithelium, however, does not protect against the deleterious effects of bleomycin, ${ }^{12}$ suggesting that the endogenous levels of this inhibitor are well tuned to govern the activity of proteinases it targets.

Recently, microarray analysis of BALB/c (which are resistant to bleomycin-induced lung injury) and C57BL/6 mice (which are susceptible to bleomycin-induced lung injury) revealed that Timp3 expression is reduced in C57BL/6 mice-compared with its elevated expression in $\mathrm{BALB} / \mathrm{C}$ - during the initial, damaging inflammatory response. ${ }^{13}$ These data predict that TIMP3 functions to moderate the host response to tissue injury. Indeed, we report that whereas TIMP3 does seem to affect early response to injury, it is critical for proper resolution of inflammation and fibrosis at later stages. These findings suggest that this natural inhibitor functions to block the activity of metalloproteinases (both MMP and ADAM) mediating proinflammatory and fibrotic pathways.

\section{Materials and Methods}

\section{Mouse Model and Treatments}

Eight-week-old Timp3 ${ }^{-1-}$ mice (C57BL/6) and wild-type littermates were anesthetized with $0.425 \mathrm{mg} / \mathrm{g} 2 \%$ avertin (Sigma-Aldrich, St. Louis, MO), intubated, and exposed by pharyngeal deposition and instillation of bleomycin $(0.0015 \mathrm{U} / \mathrm{g})$ or an equal volume of PBS. For some studies, mice were given i.p. injections of GM6001 (20 mg/kg in carboxymethyl cellulose; Sigma-Aldrich) or vehicle (carboxymethyl cellulose) on days 4,5 , and 6 post-bleomycin. Mice were sacrificed at the indicated time, up to 28 days post-bleomycin. Lungs were harvested and lavaged twice with PBS (1 ml/lavage). Bronchoalveolar lavage (BAL) was spun at $500 \mathrm{rcf}$ for 10 minutes at $4^{\circ} \mathrm{C}$, and the supernatant was aliquoted and flash frozen in liquid nitrogen. Pelleted cells were suspended in $1 \mathrm{ml}$ of red blood cell lysis buffer (eBioscience, San Diego, CA), incubated on ice for 5 minutes, washed in PBS, and resuspended in Dulbecco's modified Eagle's medium. Cell concentration was measured using the EasyCount System (Dynacell Life Sciences, Ambler, PA). Cell differentials were done with cytospun cells as described previously. ${ }^{9}$ Lavaged lungs were fixed by inflating to $20 \mathrm{~cm} \mathrm{H}_{2} \mathrm{O}$ in PBSbuffered paraformaldehyde or were snap frozen in liquid nitrogen for RNA and protein analysis. These protocols have been approved by the Institutional Animal Care and Use Committee at the University of Washington.

\section{Protein Assays}

BAL samples were assayed for total protein using the Quick Start Bradford Protein Assay Kit (Bio-Rad, Hercules, CA) and total IgM concentration using a mouse IgM enzyme-linked immunosorbent assay (ELISA) (Bethyl Laboratories, Montgomery, TX). Levels of 13 inflam- matory factors (granulocyte-macrophage colony-stimulating factor, interferon $\gamma$, interleukin (IL)-1 $\beta, \mathrm{IL}-2, \mathrm{IL}-4$, IL-5, IL-10, IL12p70, IL-13, IL-17, CCL2/JE, CXCL1/KC, CXCL2/macrophage inflammatory protein 2 (MIP2), $\mathrm{TNF} \alpha$, and vascular endothelial growth factor) were assessed in BAL fluid and lung homogenate using a Fluorokine MAP Multiplex Mouse Cytokine Panel (R\&D Systems, Minneapolis, MN) on a Luminex BioPlex System with BioPlex control software (version 4.0; Bio-Rad). To measure total collagen deposition, lung homogenates were quantified by sircol assay according to the manufacturer's instructions (Biocolor, Carrick Fergus, U.K.).

\section{Myeloperoxidase ELISA}

Lungs were homogenized in tissue lysis buffer (SigmaAldrich) with a proteinase inhibitor mixture pill (Roche Applied Science, Indianapolis, IN), aliquoted, and snap frozen in liquid nitrogen. Aliquots of BAL fluid and lung homogenate from wild-type and Timp3 $3^{-1-}$ mice treated with PBS or bleomycin from all time points were analyzed for myeloperoxidase (MPO) abundance. Wells of a 96well plate were incubated with capture antibody overnight at room temperature $(1 \mu \mathrm{g} / \mathrm{ml}$ anti-human/mouse MPO, AF3667; R\&D Systems) and then washed three times with PBS and $0.05 \%$ Tween (PBST). Wells were blocked with PBS and $5 \%$ bovine serum albumin (BSA) for 1 hour, washed with PBST, and incubated with sample or standard $(0.4$ to $250 \mathrm{ng} / \mathrm{ml})$ overnight at $4^{\circ} \mathrm{C}$. Wells were again washed with PBST and then incubated with detection antibody $(0.25 \mu \mathrm{g} / \mathrm{ml}$ anti-mouse MPO, HM1051BT; Hycult Biotechnology, Uden, The Netherlands). After 2 hours, wells were washed with PBST and then incubated with streptavidin conjugated to HRP for 20 minutes. Wells were washed with PBST and tetramethylbenzidine substrate (Sigma-Aldrich) was added to each well and incubated for 5 to 20 minutes. $0.5 \mathrm{M} \mathrm{H}_{2} \mathrm{SO}_{4}$ was used to stop the reaction, and plates were read at $450 \mathrm{~nm}$ using a Synergy 4 Multi-Mode Microplate Reader (BioTek, Winooski, VT).

\section{Metalloproteinase Activity}

The OmniMMP fluorogenic substrate (P-126; Biomol International, Plymouth Meeting, PA) was used to analyze total metalloproteinase activity in BAL and lung homogenates. Samples (25 to $50 \mu \mathrm{l}$ ) were added to 96-well plates and warmed to $37^{\circ} \mathrm{C}$. Substrate was added to each well, and the plate was read immediately (excitation: $328 \mathrm{~nm}$; emission: $393 \mathrm{~nm}$ ) and then again at 1.5, 3, $6,12,30,60,120$, and 240 minutes with a Synergy 4 (BioTek). The increase in fluorescence was plotted against time, and the slope of the line, which indicates metalloproteinase activity, determined using GraphPad Prism for Macintosh version 4.0c (GraphPad Software, San Diego, CA).

\section{Isolation of Bone Marrow-Derived Neutrophils}

Neutrophils were isolated from mouse bone marrow as described previously. ${ }^{14}$ Mice were euthanized, the femur 
and the tibia of both hind legs removed and freed of all soft tissue, and the tips of each removed. The bottom of a 0.6-ml tube was punctured with an 18-gauge needle, and the $0.6-\mathrm{ml}$ tube was placed inside a $1.5-\mathrm{ml}$ tube. Each bone was placed in the 0.6-ml Eppendorf tube with the proximal portion of the bone down, and the tubes were spun at 3000 ref for 30 seconds. The 0.6-ml tube and bone were then discarded; each cell pellet was resuspended in $1 \mathrm{ml}$ of HBSS (Invitrogen, Carlsbad, CA) with EDTA (HBSS without calcium, magnesium, phenol red, and sodium bicarbonate ( $\mathrm{pH}$ 7.2), $15 \mathrm{mmol} / \mathrm{L}$ EDTA, and $1 \% \mathrm{BSA}$ ), and cells were then spun at 400 ref for 10 minutes at room temperature. The cell pellet was then resuspended in $1 \mathrm{ml}$ of HBSS-EDTA, layered on a threelayer Percoll gradient of 78,69 , and 52\% Percoll diluted in HBSS (100\% Percoll was nine parts Percoll and one part 10× HBSS; GE Healthcare, Piscataway, NJ) and spun at 1500 ref for 40 minutes at room temperature. The cells were then collected from the 69\%/78\% interface and the upper part of the $78 \%$ layer, placed in tubes coated with $1 \% \mathrm{BSA}$, and washed with HBSS-EDTA. Cells were treated with red cell lysis buffer (eBioscience), washed with PBS and $1 \%$ BSA, and the cell pellet was resuspended in HEPES buffer $(140 \mathrm{mmol} / \mathrm{L} \mathrm{NaCl}, 5 \mathrm{mmol} / \mathrm{L}$ $\mathrm{KCl}, 1 \mathrm{mmol} / \mathrm{L} \mathrm{MgCl}, 2 \mathrm{mmol} / \mathrm{L} \mathrm{CaCl}$, and $10 \mathrm{mmol} / \mathrm{L}$ HEPES ( $\mathrm{pH} 7.2))$. Cell concentration was measured using the EasyCount System (Dynacell Life Sciences), and cell differentials were done with cytospun cells to ensure purity of cell population (cells obtained were $>95 \%$ neutrophils). Cells were then stained and used in migration and apoptosis studies as described below.

\section{Measurement of Neutrophil Chemotaxis in Vitro}

Wild-type and Timp3 $3^{-1-}$ neutrophil chemotaxis toward BAL fluid from wild-type and Timp3 $3^{-1-}$ mice was measured using a fluorescence-based microchemotaxis assay with human neutrophils as described previously. ${ }^{15}$ Mouse neutrophils were recovered from bone marrow (described above). After isolation, neutrophils were labeled with calcein AM $(5 \mu \mathrm{g} / \mathrm{ml}$; Molecular Probes, Eugene, OR) for 30 minutes, washed twice in PBS, and resuspended at a concentration of $3 \times 10^{6} / \mathrm{ml}$. Briefly, the wells of a 96-well plate were filled with BAL fluid. Polycarbonate filters with 8- $\mu \mathrm{m}$-sized pores were placed on the 96-well plate, and calcein-labeled neutrophils were added to the top of the filter at sites directly over each of the wells of the plate. The chemotaxis chamber, consisting of the filter chambers and 96-well plate, was incubated for 30 minutes $\left(37^{\circ} \mathrm{C}\right.$ and $\left.5 \% \mathrm{CO}_{2}\right)$. Nonmigrating neutrophils were removed from the upper side of the filter. The chemotaxis chamber was placed in the Synergy 4 (BioTek), and the migrated cells were measured using the calcein fluorescence signal (excitation: $485 \mathrm{~nm}$; emission, $530 \mathrm{~nm}$ ). Neutrophil migration was expressed as a percentage of the total number of neutrophils that were placed on the topside of the filter (\% total).

\section{Neutrophil Apoptosis Analysis}

BAL cells from wild-type and Timp3 ${ }^{-1-}$ mice at 7 and 14 days post-bleomycin were isolated, red blood cells lysed (eBioscience), and the number of leukocytes determined (EasyCount System; Dynacell Life Sciences). Leukocytes $\left(2 \times 10^{5} /\right.$ animal $)$ were then stained with antisera against Ly6C/Ly6G conjugated to phycoerythrin (12-5931; eBioscience) and then washed three times in PBS with $1 \%$ BSA. Cells were then incubated with Annexin VFITC according to the manufacturer's protocol (BioVision, Mountain View, CA), and then the percentage of apoptotic neutrophils was determined using the EasyCyte Plus Guava System (Millipore, Billerica, MA). Bone marrowderived neutrophils were used as a positive control for these studies.

As well, bone marrow-derived neutrophils were isolated from wild-type and $\mathrm{Timp}^{-1-}$ mice as described above. Cells $\left(5 \times 10^{4} /\right.$ well $)$ were then stimulated in a 96-well plate with PBS, staurosporine ( $2 \mu \mathrm{mol} / \mathrm{L})$, or TNF $\alpha$ $\left(20 \mathrm{pg} / \mathrm{ml}\right.$ ) for 2 hours at $37^{\circ} \mathrm{C}$. The concentration and stimulation time was determined by initially conducting the study using a time course (30 minutes to 4 hours of stimulation) and a concentration gradient ( 0.5 to $2 \mu \mathrm{mol} / \mathrm{L}$ for staurosporine and 5 to $20 \mathrm{pg} / \mathrm{ml}$ for TNF $\alpha$ ). After stimulation, the number of neutrophils undergoing apoptosis was determined using the Apo 3/7 High-Throughput Screen for caspase 3/7 activity, according to the manufacturers protocols (Cell Technology, Mountain View, CA). Briefly, cells were lysed and incubated at $37^{\circ} \mathrm{C}$ with caspase $3 / 7$ detection reagent for 15 minutes to 1 hour with the amount of fluorescence (excitation: 488 $\mathrm{nm}$; emission: $530 \mathrm{~nm}$ ) determined with the Synergy 4 (BioTek).

\section{Quantitative RT-PCR}

Total lung RNA was isolated with TRIzol (Invitrogen), and the quantity and quality of RNA were determined using a NanoDrop spectrophotometer (NanoDrop, Wilmington $\mathrm{DE})$. Primers and TaqMan probes (6-carboxyfluorescein dye-labeled) for TIMP3 and glyceraldehyde-3-phosphate dehydrogenase were added to cDNA synthesized from 5 $\mu \mathrm{g}$ of total RNA with a High-Capacity cDNA Archive kit (Applied Biosystems). Additionally, $5 \mu \mathrm{g}$ of total RNA was added to either an $\mathrm{RT}^{2}$ Profiler PCR Array for Extracellular Matrix and Adhesion Molecules or an $\mathrm{RT}^{2}$ Profiler PCR Array for Mouse Inflammatory Cytokines and Receptors (PAMM013E-4 or PAMM-011E-4, respectively; SABiosciences, Frederick, MD) to assess multiple Mmps, Timps, chemokines, and cytokines. Product amplification was measured with an ABI HT7900 Fast Real-Time PCR System, and the threshold cycle $(\mathrm{Ct})$ was obtained from duplicate samples and averaged. The $\Delta \mathrm{Ct}$ was the difference between the average $\mathrm{Ct}$ for the specific cDNAs and the endogenous control gene, in our case, hypoxanthine phosphoribosyltransferase. The $\Delta \Delta \mathrm{Ct}$ for analysis of Timp3 expression in wild-type mice following bleomycin was the result of the average $\Delta \mathrm{Ct}$ at a given time point minus the average $\Delta \mathrm{Ct}$ of day 0 (PBS control) samples. For the PCR arrays, the $\Delta \Delta C t$ 
was the result of the average $\Delta \mathrm{Ct}$ at a given time point in the Timp3 $3^{-1-}$ mice minus the average $\Delta \mathrm{Ct}$ of the wild-type samples at the same time point. The data are expressed as relative quantification, which is the fold change from the average of the baseline expression in the PBS control (for Timp3 expression) or from the average expression in wildtype mice (for the PCR arrays) and is calculated as $2^{-\Delta \Delta C t}$.

\section{Statistics}

Assessment of statistical significance was done using GraphPad Prism for Macintosh version 4.0c (GraphPad Software). Appropriate methods, including unpaired $t$-tests, one-way ANOVAs with a Tukey posthoc test, and two-way ANOVAs with a Bonferroni posthoc test were used for each experiment (indicated in figure legends) and $P<$ 0.05 was considered significant. All graphs include error bars $( \pm$ SEM) and experiments were replicated at least two times. A minimum of four PBS-treated mice were collected for both genotypes at days $1,3,7$, and 14 , and a minimum of eight bleomycin-treated mice were collected for both genotypes at days $1,3,7,14$, and 28 .

\section{Results}

\section{Neutrophil Influx Is Increased in Timp3 ${ }^{-/-}$Mice}

The effect of TIMP3 deletion on lung inflammation and repair following injury was evaluated by treatment of Timp3 ${ }^{-1-}$ mice with bleomycin. Following bleomycin injury, the influx of inflammatory cells into BAL did not differ between Timp3 $3^{-1-}$ and wild-type mice up to day 7 postinjury (Figure 1A). Thereafter, Timp3 ${ }^{-1-}$ mice had a markedly elevated and persistent inflammatory response (Figure 1A) due largely to a pronounced increase in the numbers of neutrophils (Figure 1B). At these later times, total lymphocytes in the BAL were also significantly increased in Timp3 ${ }^{-1-}$ mice compared with wild-type, although not to the same extent as neutrophils (5-fold increase in lymphocytes versus 85-fold increase in neutrophils; Figure 1B). Compared with wild-type mice, MPO levels were significantly increased in Timp3 $3^{-1-}$ mice at 14 and 28 days post-injury (Figure 1C), confirming the cell-number data.

The morphology of 8-week-old control lungs did not differ between genotypes (Figure 2A). In contrast, on H\&E-stained sections from injured wild-type and Timp3 ${ }^{-1-}$ mice, we observed that the pattern of inflammatory cell dispersion throughout the injured lungs was altered in the absence of TIMP3. At 7 days post-injury, inflammatory cells appeared localized around vessels and along the periphery of wild-type lungs, whereas cells were dispersed throughout the lungs from Timp $3^{-\prime-}$ mice (Figure 2A). Overall inflammation within lung tissue at day 7, however, did not differ between genotypes (Figure 2A), and MPO levels demonstrated that neutrophils numbers were also similar at this time (Figure 2B). At day 28, inflammation was confined to focal lesions in wild-type lungs, which also had large regions of normal-appearing alveoli. However, at this same time, extensive inflamma-

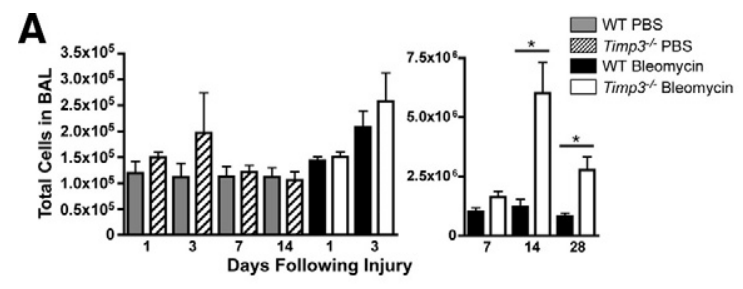

B
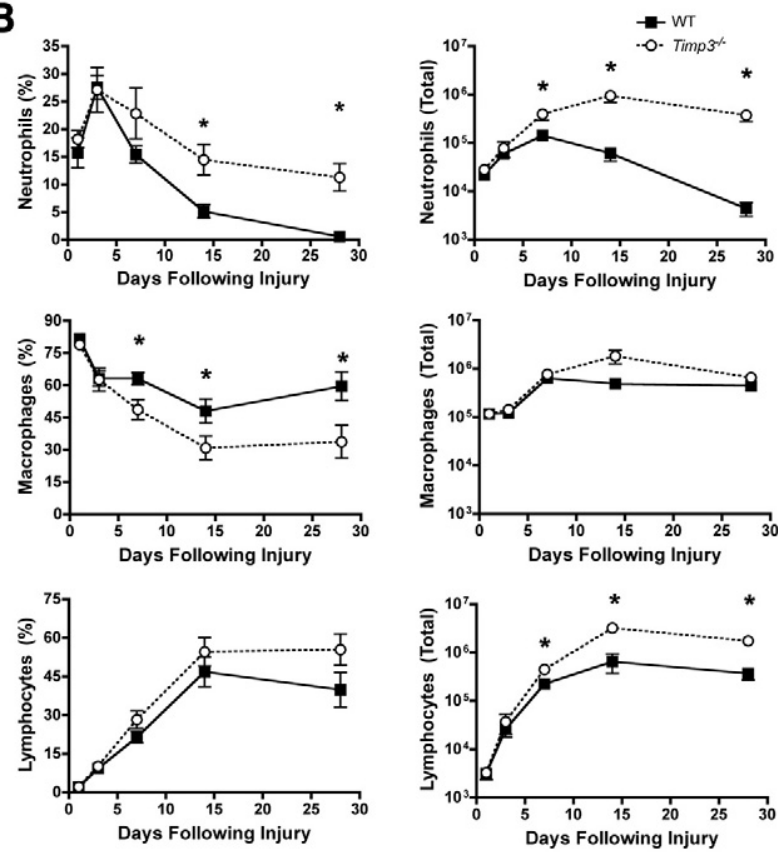

C

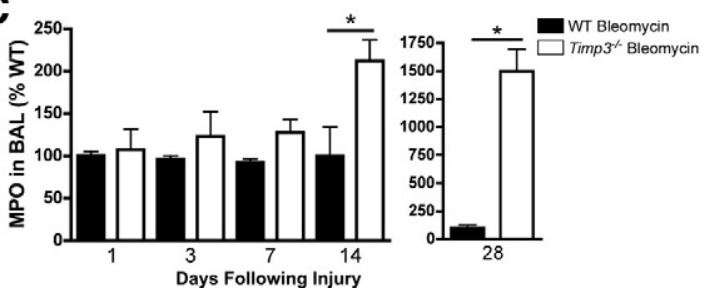

Figure 1. Neutrophil accumulation is increased in the lungs of Timp $3^{-1-}$ mice following treatment with bleomycin. A: Total number of inflammatory cells in the BAL fluid of Timp $3^{-/-}$mice was significantly increased compared with wild-type (WT) mice at day 14 and $28\left({ }^{*} P<0.05\right.$; two-way analysis of variance with Bonferroni posthoc test between genotypes and treatment groups at each time point; $n=4-18$ ). B: Examination of the different leukocyte populations present in the BAL fluid of wild-type and Timp $3^{-/-}$ mice revealed that total neutrophil numbers were significantly increased at days 7,14 , and 28 , and the percent neutrophils was significantly increased at days 14 and $28\left({ }^{*} P<0.05\right.$, two-way analysis of variance with Bonferroni posthoc test between genotypes and treatment groups at each time point; $n=4-18)$. This difference suggests that increased neutrophil abundance is responsible for the increased total inflammatory cells observed in the Timp $3^{-/-}$lungs. Total lymphocytes were also significantly increased at days 7,14 , and 28 but not to the same extent as neutrophils. C: Examination of total MPO abundance in the BAL fluid by ELISA revealed a significant increase in MPO at days 14 and 28 in the absence of TIMP3, confirming the increase in neutrophil number already observed in these mice $\left({ }^{*} P<0.05\right.$, unpaired $t$-test between genotypes at each time point; $n=3-11$ ). Abundance of MPO in wild-type mice was set to $100 \%$ for each time point.

tion, elevated MPO levels, and tissue damage were clearly seen in all Timp3 ${ }^{-1-}$ lungs (Figure 2).

Morphometric and biochemical analyses were also used to compare lung collagen content between wildtype and Timp3 ${ }^{-1-}$ mice. In the absence of TIMP3, the abundance of deposited collagen was significantly in- 
A
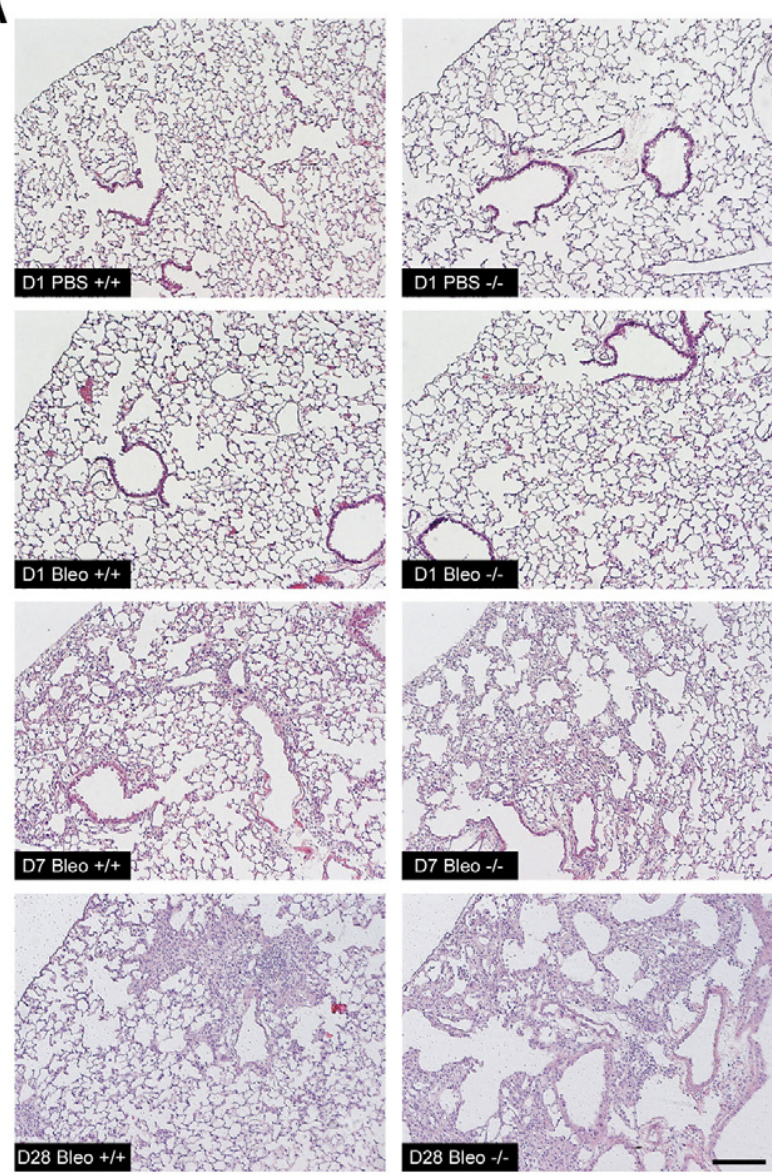

B

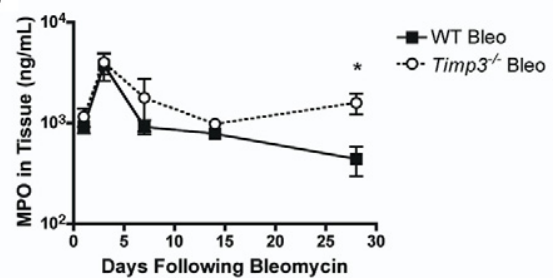

Figure 2. Inflammatory cells appear more diffuse and increased MPO abundance suggests significantly more neutrophils within the lung interstitium of mice lacking TIMP3. A: H\&E-stained lung sections from PBS and bleomycintreated wild-type (WT) and Timp $3^{-/-}$mice 1,7 , and 28 days post-treatment. Inflammatory cells appear to be more diffuse and spread throughout the interstitium in the absence of TIMP3 at 7 days post-injury (scale bar, $250 \mu \mathrm{m}$ ). B: Examination of total MPO abundance in lung homogenate by ELISA revealed a significant increase in MPO at day 28 in the absence of TIMP3, suggesting an increase in neutrophil abundance in the lung interstitium of Timp $3^{-1-}$ mice ( $P<0.05$, unpaired $t$-test between genotypes at each time point; $n=3-4$ )

creased at day 14 and remained elevated at day 28 (Supplemental Figure S1, see http://ajp.amjpathol.org). Analysis of Gomori-stained lung sections also revealed a pattern of persistent and more extensive collagen deposition in Timp3 ${ }^{-1-}$ mice. At day 14 , collagen localization in Timp3 ${ }^{-1-}$ mice was characterized by a thickening of the alveolar walls and loss of alveolar septa, as opposed to the predominantly peripleural lesions observed in wild-type mice, and these features were still apparent, if not exaggerated, at day 28 (Supplemental Figure S1A, see http://ajp.amjpathol.org). Furthermore, al-
A

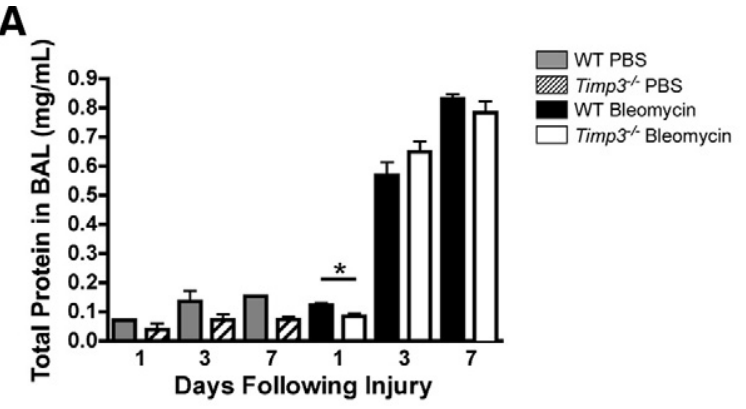

B

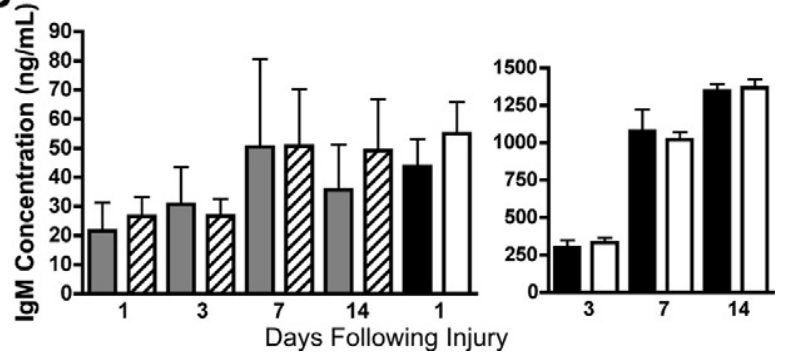

Figure 3. Total lung injury is similar in both wild-type (WT) and Timp $3^{-/}$ mice following bleomycin-induced injury. A: Total BAL fluid protein, as determined by a Bradford assay, was similar in wild-type and Timp $3^{-/-}$mice at days 1,3 , and $7\left({ }^{*} P<0.05\right.$, two-way analysis of variance with Bonferroni posthoc test between genotypes and treatment groups at each time point; $n=3-5$ ). B: Analysis of IgM abundance in BAL fluid by ELISA detected no significant differences between the genotypes at days $1,3,7$, or 14 (two-way analysis of variance with Bonferroni posthoc test between genotypes and treatment groups at each time point; $n=3-9$ ).

though increased collagen levels began to resolve in the wild-type by day 28, collagen abundance was still increased in the Timp3 ${ }^{-1-}$ mice (Supplemental Figure S1B, see http://ajp.amjpathol.org). Taken together, these studies suggest a role for TIMP3 in the later stages of wound repair following lung injury.

\section{Acute Injury Is Similar in Wild-Type and Timp3 ${ }^{-1-}$ Mice}

The extent of acute injury in wild-type and Timp3 $3^{-1-}$ mice was examined by measuring total protein and IgM levels in the BAL fluid during the first week of injury (Figure 3A). We detected no difference in either marker between genotypes (Figure 3A). These data suggest that TIMP3 does not influence the extent of alveolar damage and vascular permeability (Figure 3B).

To assess if the increased neutrophil accumulation correlated with Timp3 expression in wild-type mice, we quantified Timp3 mRNA levels following bleomycin-induced lung injury. Expression of Timp3 decreased immediately following injury to day 3 but then increased steadily thereafter (Figure 4). Thus, when TIMP3 levels were being restored in wild-type mice, persistent inflammation and tissue damage were evident in Timp3 ${ }^{-1-}$ mice, suggesting that TIMP3 has an important role in the resolution of inflammation following lung injury. 


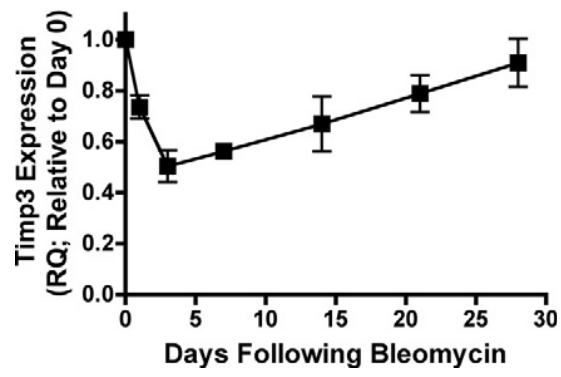

Figure 4. Timp3 expression decreases immediately following bleomycininduced injury. Quantitative PCR analysis revealed that the expression of Timp3 in injured lung (relative to uninjured lung) is significantly reduced at days 3,7 , and 14 and returns to uninjured levels by day 21 (Timp3 $\mathrm{Ct}$ range $=$ $19-22$; Hprt average $\mathrm{Ct}=23 ; n=3-8$ ).

\section{Increased MMP Activity in Timp3 ${ }^{-1-}$ Mice}

We measured total MMP activity in both BAL fluid and lung tissue to determine whether it differed between wildtype and Timp3 ${ }^{-1-}$ mice. Although an increase in BAL MMP activity was detected in Timp3 $3^{-1-}$ mice at 1 day post-injury, no significant differences were observed between BAL samples at any other time point (Figure 5A). In contrast, in the tissue, where TIMP3 is localized and concentrated, MMP activity was increased at both 14 and 28 days following bleomycin (Figure $5, \mathrm{~B}$ and $\mathrm{C}$ ). ${ }^{16,17}$

To assess if increased MMP activity was due to increased production of specific enzymes, we examined the expression and protein levels of several Mmps in lung tissue from wild-type and Timp3 ${ }^{-1-}$ mice following injury with bleomycin. The expression of most MMPs examined increased in wild-type mice in response to bleomycin injury (Supplemental Figure S2A, see http://ajp. amjpathol.org), and with few exceptions, the levels of these mRNA were similarly affected in Timp3 ${ }^{-1-}$ mice (Supplemental Figure S2B, see http://ajp.amjpathol.org). The expression of Mmp7 was more than five-fold increased in the lungs of Timp3 ${ }^{-1-}$ mice (Supplemental Figure S2B, see http://ajp.amjpathol.org); however, exam- ination of MMP7 levels by casein zymography showed no difference in the levels of the pro- or activated enzyme between genotypes (data not shown). Mmp12 mRNA levels were also elevated in Timp3 ${ }^{-1-}$ mice, but because this proteinase is a macrophage-specific product, this increase is likely due to the presence of more macrophages (Figure 1B). Additionally, examination of MMP2 and 9 levels by gelatin zymography did not reveal a significant difference between wild-type and Timp3 ${ }^{-1-}$ mice (data not shown). Timp1 expression also did not differ much between wild-type and Timp3 $3^{-/-}$mice, suggesting a lack of compensation by this inhibitor.

To determine whether the increase in neutrophil accumulation in Timp3 ${ }^{-/-}$mice was due to uninhibited metalloproteinase activity, we treated wild-type and Timp3 ${ }^{-/-}$ mice with vehicle or GM6001, a broad spectrum synthetic inhibitor of metalloproteinases, at days 4, 5, and 6 following bleomycin injury. In agreement with the data in Figure 1, bleomycin-injured Timp3 ${ }^{-1-}$ mice treated with vehicle had increased neutrophil accumulation in their lungs at day 7 compared with wild-type mice (177\%; Figure 5D). Blocking MMP activity reduced neutrophil counts in injured wild-type mice and completely restored the phenotype seen in Timp3 ${ }^{-1-}$ mice (Figure 5D).

\section{Increased Chemotaxis Activity in Timp3 ${ }^{-1-}$ Mice}

We next assessed if differences in chemotactic activity could account for increased neutrophil accumulation in Timp3 $3^{-1-}$ mice. Using a rapid fluorescence-based assay, we first examined the ability of wild-type and Timp $3^{-1-}$ neutrophils to migrate to BAL harvested from bleomycintreated wild-type mice at $3,7,14$, and 28 days post-injury (Figure 6A). Although Timp3 ${ }^{-1-}$ neutrophils appeared to have slightly higher chemotaxis to day $3 \mathrm{BAL}$ fluid, no significant differences were observed, indicating that wild-type and Timp3 $^{-1-}$ neutrophils had similar chemo-
A

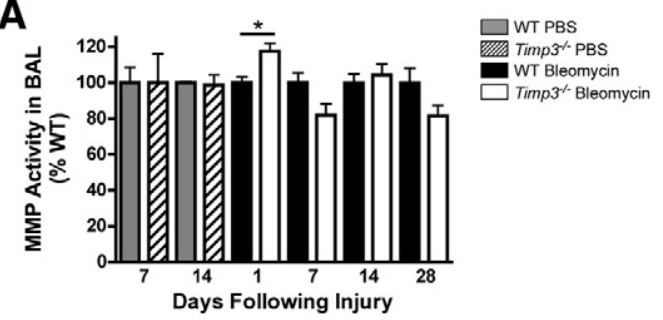

C

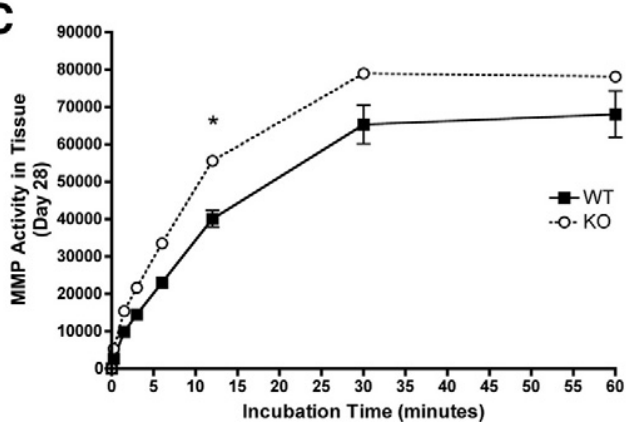

B

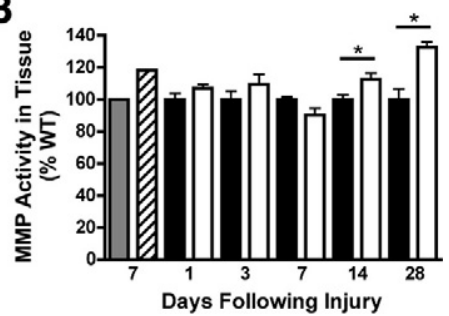

D

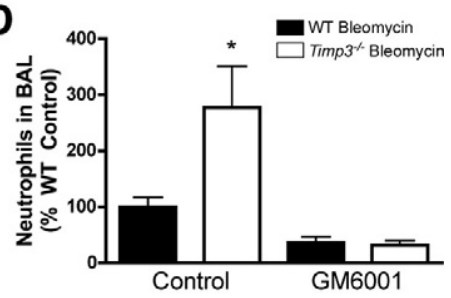

Figure 5. MMP activity within the lung homogenate is increased in the absence of TIMP3. A: Examination of MMP activity in BAL fluid by fluorometric cleavage assay revealed a significant increase only at day 1 in Timp $3^{-1-}$ mice $\left({ }^{*} P<0.05\right.$, unpaired $t$-test between genotypes at each time point; $n=3-8$ ). MMP activity in wild-type (WT) mice was set to $100 \%$ for each time point. B: MMP activity in lung tissue, as determined by fluorometric cleavage assay, was significantly increased in the absence of TIMP3 at days 14 and $28\left({ }^{*} P<0.05\right.$, unpaired $t$-test between genotypes at each time point; $n=3-6$ ). MMP activity in wild-type mice was set to $100 \%$ for each time point. C: Representative graph of MMP activity in lung homogenate (indicated by increase in relative fluorescence over time) from wild-type and Timp $3^{-1-}$ mice at day $28\left({ }^{*} P<0.05\right.$, linear regression for each genotype; $n=2$ ). D: Treatment of mice with a synthetic inhibitor of metalloproteinases, GM6001, at days 4, 5, and 6 following injury abolishes the increase in neutrophil abundance in Timp3 $3^{-/-}$mice at day 7 (two-way analysis of variance with Bonferroni posthoc test between genotypes and treatment groups at each time point; $n=4$ ). 
A
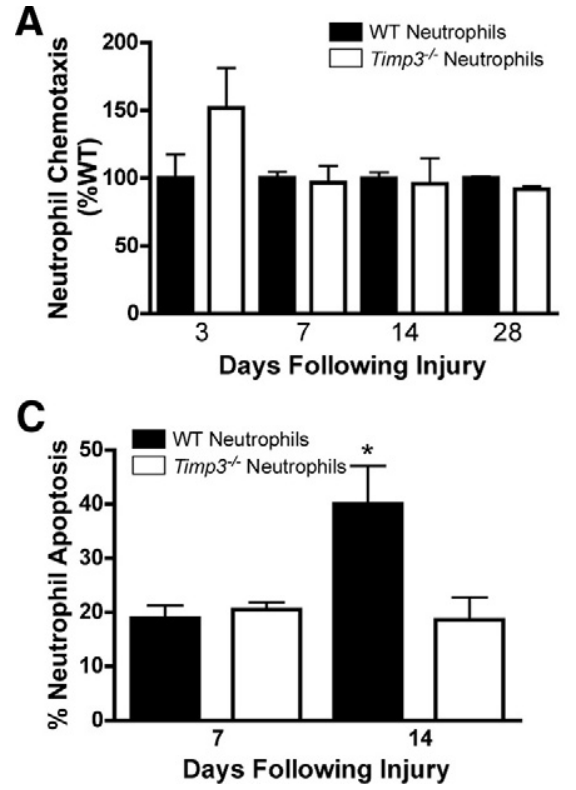

B

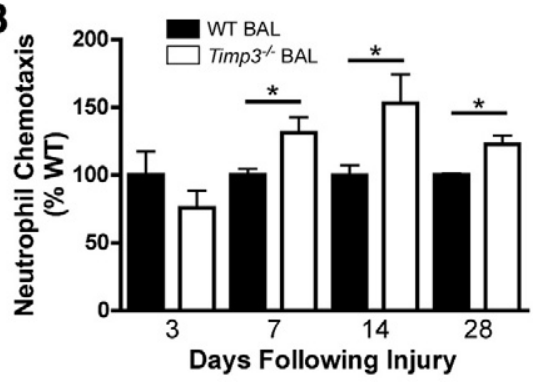

D

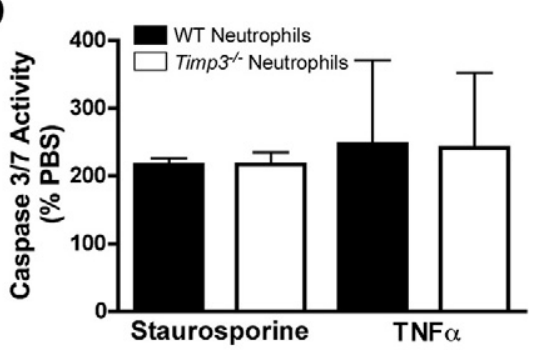

Figure 6. Neutrophil chemotaxis to BAL fluid from Timp $3^{-1-}$ mice is significantly increased compared with wild-type (WT) mice. A: Wildtype and Timp3 $3^{-1-}$ neutrophils were found to have similar chemotactic properties in response to wild-type BAL fluid (unpaired $t$-test between genotypes at each time point; $n=3-12$ ). B: BAI fluid from Timp3 $3^{-1-}$ mice 7, 14, and 28 days after bleomycin was found to induce significantly more neutrophil chemotaxis than wildtype BAL fluid from the same time points $\left({ }^{*} P<\right.$ 0.05 , unpaired $t$-test between genotypes at each time point; $n=3-13)$. C: Identification of apoptotic cells by flow cytometry revealed that the percentage of BAL neutrophils from wild-type mice undergoing apoptosis at day 14 was significantly increased compared with wild-type mice at day 7 and Timp $3^{-1-}$ mice at both days 7 and $14\left({ }^{*} P<0.05\right.$, one-way analysis of variance with Tukey posthoc test; $n=4-9)$. D: Analysis of caspase $3 / 7$ activity revealed that the ability to initiate apoptosis in response to staurosporine or TNF $\alpha$ was similar in both wild-type and Timp $3^{-\prime-}$ neutrophils (unpaired $t$-test between genotypes at each time point; $n=3$ ). tactic abilities. We then compared the migration of wildtype neutrophils to BAL from bleomycin-injured wild-type or Timp3 ${ }^{-1-}$ mice and found greater chemotactic activity in the Timp3 $3^{-1-}$ samples at 7,14 , and 28 days postinjury (Figure 6B), the same times when increased neutrophil accumulation was apparent in vivo (Figure 1).

To assess if the accumulation of neutrophils in Timp3 $3^{-1-}$ mice was due to continued influx or impaired clearance, we quantified by flow cytometry the percentage of neutrophils in BAL undergoing apoptosis in wildtype and Timp3 ${ }^{-1-}$ mice. At day 7 , no differences were observed between genotypes (Figure 6C). At 14 days post-bleomycin, the percentage of apoptotic neutrophils in wild-type BAL increased significantly compared with the levels at day 7 (Figure 6C). However, at day 14, the percentage of apoptotic neutrophils did not increase in Timp3 $^{-1-}$ mice. We also examined caspase 3/7 activity in wild-type and Timp3 $^{-1-}$ bone marrow-derived neutrophils and found that both staurosporine and TNF $\alpha$ induced similar amounts of caspase activity, indicating that the ability of neutrophils to undergo apoptosis was not altered in the absence of TIMP3 (Figure 6D). The static level of neutrophil apoptosis in Timp3 ${ }^{-1-}$ mice provide further evidence that continued influx was responsible for the prolonged increased accumulation of these granulocytes.

\section{Anti-Inflammatory Markers Are Impaired in Timp3 $^{-/-}$Mice}

To begin to identify the mechanism responsible for the increased chemotaxis, we determined the levels of key inflammatory mediators in BAL fluid and lung homogenate from wild-type and Timp3 ${ }^{-1-}$ mice. Although we detected some differences, the levels of KC and MIP2, potent neutrophil chemokines, were similar in both BAL and lung homogenates from wild-type and Timp3 ${ }^{-1-}$ mice following injury (Figure 7, A and B). TNF $\alpha$ abun- dance in BAL and lung homogenate was also examined, and no differences were observed between genotypes (data not shown). We also found that both IL10 and IL13 were reduced in Timp3 $3^{-1-}$ mice compared with wild-type mice at 14 and 28 days post-injury; however, only IL 13 abundance was significantly reduced (Figure 7, C and D). Furthermore, we examined the expression of many inflammatory mediators in wild-type and Timp3 $3^{-1-}$ lungs following injury. Although we found that there were few differences, surprisingly, there was a striking trend toward impaired expression of both pro- and anti-inflammatory mediators by 14 days postinjury (Supplemental Figure S2, see http://ajp.amjpathol.org). This also included a reduction in 113 expression, which provided support for our data looking at IL13 protein levels (Figure 7D).

\section{Discussion}

An important component of the tissue response to acute injury is an inflammatory response, which functions to mitigate potential infection and to influence and perform several reparative processes, such as the resolution of scar formation. ${ }^{1}$ Metalloproteinases, such as MMPs and ADAMs, have emerged as critical effector enzymes controlling both pro- and anti-inflammatory pathways. ${ }^{2,4,18}$ Consequently, regulation of metalloproteinase activity would sit high in hierarchy of processes that shape an inflammatory response, and thus, their inhibitors, the TIMPs, are also important players during tissue repair. ${ }^{9,11,19-21}$ In the current study, we extend this paradigm, demonstrating that TIMP3 is integral to regulating resolution of inflammation following bleomycin-induced lung injury.

In other studies, TIMP3 was shown to moderate inflammation by regulating ADAM17 activity, thereby governing the release of TNF $\alpha$ from the cell surface.,22 In the ab- 
A
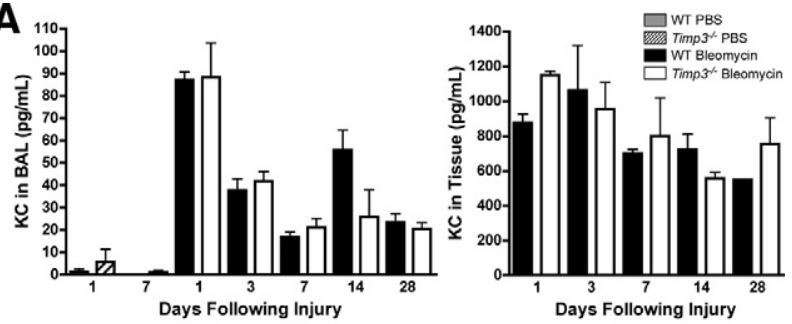

B
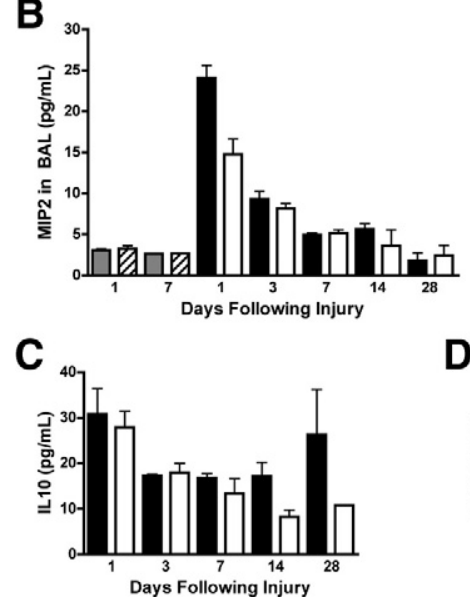

D
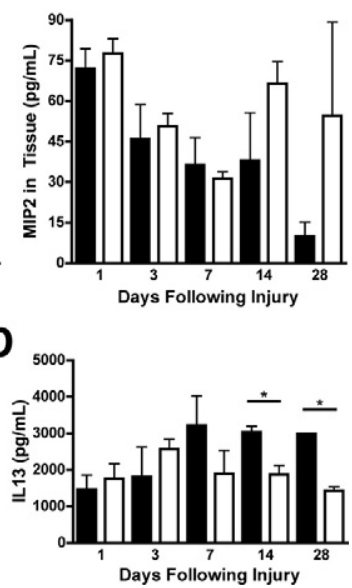

Figure 7. Markers of inflammatory resolution are reduced in Timp $3^{-/-}$mice. $\mathbf{A}$ and B: The abundance of pro-inflammatory mediators, including $\mathrm{KC}(\mathbf{A})$ and MIP2 (B), was analyzed in BAL fluid (left panels) and lung homogenate (right panels) in wild-type (WT) and Timp $3^{-1-}$ mice. No consistent significant differences were observed between genotypes in BAL fluid (two-way analysis of variance with Bonferroni posthoc test between genotypes and treatment groups at each time point; $n=3-4$ ) or in lung homogenate (one-way analysis of variance with Tukey posthoc test; $n=3-4$ ). C and $\mathbf{D}$ : The abundance of the anti-inflammatory cytokines IL10 (C) and IL13 (D) was analyzed in lung homogenate from wild-type and Timp $3^{-1-}$ mice. Both cytokines were reduced at days 14 and 28 in mice lacking TIMP3; however, this difference was only significant for IL13 $\left({ }^{*} P<0.05\right.$, one-way analysis of variance with Tukey posthoc test; $n=3-4$ ).

sence of TIMP3, TNF $\alpha$ shedding and activity are increased following injury or infection, leading to a marked acute inflammatory response and in some cases enhanced mortality. ${ }^{6,7}$ TIMP3 is also highly expressed in the lungs ${ }^{23,24}$; thus, our initial hypothesis was that following bleomycin-induced lung injury, inflammation would be significantly increased due to enhanced TNF $\alpha$ shedding, ultimately leading to diminished survival. Although our data do demonstrate that inflammation was increased in Timp3 $3^{-1-}$ mice, we saw no difference in the levels of $\mathrm{TNF} \alpha$ in lung or BAL between genotypes. Our findings suggest that in response to lung injury TIMP3 does not moderate activation of TNF $\alpha$, unlike that shown in other tissues. In further contrast to other models, increased inflammation in lungs of Timp3 $3^{-1-}$ mice was not seen until the later stages of injury. TNF $\alpha$ is considered to be an early response inflammatory cytokine, ${ }^{25}$ and a lack of a TIMP3-mediated control over its levels is consistent with the later phenotypes we observed.

The pattern of Timp3 expression following bleomycin injury supports our conclusion that this inhibitor functions more predominantly in the later stages of inflammation and repair. Timp3 is expressed at high levels in the lung ${ }^{24}$; and in response to bleomycin, its mRNA levels decreased $\sim 50 \%$ by day 3 and then increased thereafter
(Figure 4). This early reduction in Timp3 expression could function to remove restraints on inflammation; however, it is also important to note that this reduction was transient and that, although there was a significant decrease in Timp3 expression compared with baseline, the level of Timp3 expression in the lung remained high. Others groups have also examined Timp3 expression following bleomycin and found that Timp3 expression was not altered at 24 hours or 14 days post-bleomycin, time points when we also saw little difference in Timp3 expression. ${ }^{26-28}$ Timp3 expression, however, appears to correlate with susceptibility to bleomycin as bleomycin-resistant BALB/C mice have significantly higher Timp3 expression following bleomycin-induced injury then C57BL/6 mice. ${ }^{13}$

As stated, TIMP3 is an effective inhibitor of both MMPs and ADAMs. ${ }^{3,29}$ Previous studies of Timp3 $3^{-1-}$ mice found increased activity or levels of specific MMPs, confirming the importance of TIMP3 in regulating the activity of some proteinases. ${ }^{5-7,30-32}$ We found that total metalloproteinase activity was significantly increased in the absence of TIMP3 (Figure 5). Interestingly, MMP activity was increased in day 14 and 28 lung homogenates of Timp3 ${ }^{-1-}$ mice, which correlates well with both the onset of neutrophilia in knockout mice and the rise in Timp3 expression in wild-type mice. Furthermore, because we detected increased metalloproteinase activity in tissue homogenates and not in BAL, we propose that TIMP3 functions to govern metalloproteinase activity in the interstitial compartment. Consistent with this idea, TIMP3 localizes to the extracellular matrix by an interaction between its N-terminus and heparan sulfate proteoglycans. ${ }^{16}$

The importance of TIMP3 regulation of metalloproteinase activity was further demonstrated by the recovery we saw in Timp3 $3^{-1-}$ mice treated repeatedly with the broadspectrum metalloproteinase inhibitor, GM6001. Whereas mice lacking TIMP3 had significantly increased neutrophils compared with wild-type mice at day 7, GM6001 completely abrogated this increase relative to wild-type levels (Figure 5D). The restoration of this phenotype supports our hypothesis that the lack of inhibiting certain metalloproteinases in Timp3 ${ }^{-1-}$ mice was responsible for the increased and persistent inflammation.

In vitro, TIMP3 can inhibit multiple MMPs, ${ }^{3,29}$ but it is not yet known which metalloproteinase or metalloproteinases TIMP3 targets to govern lung inflammation. In agreement with Swiderski et al, ${ }^{27}$ we found increased expression of several MMPs, including Mmp12 and 13, in wild-type mice following bleomycin-induced injury, but overall, we found few differences in Mmp expression between wild-type and Timp3 $3^{-1-}$ mice. Relative to their levels in wild-type mice, Mmp1a and 13 were increased at day 14, and Mmp12 was increased at days 1, 3, and 14 in mice lacking TIMP3. However, these differences were relatively modest and could be secondary to increased inflammation.

Although bleomycin-injured $M m p 7^{-1-}$ mice reveal phenotypes that appear opposite to those seen in Timp3 $3^{-1-}$ mice, there are important distinctions between these animals that do not support the idea that TIMP3 inhibits MMP7. As we reported, ${ }^{9}$ neutrophil influx into the 
lung does not differ between wild-type and $M m p 7^{-1-}$ mice. The prominent phenotype we found is the inability of neutrophils to advance across the alveolar/airway epithelium of $\mathrm{Mmp}^{-1-}$ mice. Furthermore, the retarded transepithelial migration of neutrophils in $\mathrm{Mmp}^{-1-}$ mice is seen only during the first 5 days postbleomycin. Thereafter, neutrophil numbers and location do not differ between genotypes. In contrast, neutrophilia in Timp3 ${ }^{-1-}$ mice was increased in both the lung and BAL compartments and persisted well beyond day 5 . In addition, whereas acute injury endpoints are attenuated in $M m p 7^{-1-}$ mice, these endpoints were not affected in Timp3 ${ }^{-1-}$ mice. Furthermore, although we detected elevated Mmp7 expression in Timp3 ${ }^{-1-}$ mice compared with wild-type lung, we found no difference in MMP7 protein levels. These negative data further support the conclusion that MMP7 is not the metalloproteinase responsible for the increased neutrophil influx observed in Timp3 $3^{-1-}$ mice. Indeed, as reported by others in our group, MMP7 is inhibited by TIMP1 in bleomycin-injured lung. ${ }^{10}$

Continued influx is the most likely explanation for the enhanced neutrophil accumulation in the lungs of Timp3 ${ }^{-1-}$ mice, and the increased neutrophil chemotactic activity in BAL from Timp3 $3^{-1-}$ lungs supports this model. In addition, the reduction in the percentage of apoptotic neutrophils in Timp3 ${ }^{-1-}$ lungs at 14 days postinjury is likely due to continued influx of non-apoptotic neutrophils. A link between TIMP3 and apoptosis has been established, ${ }^{33,34}$ but the exact role that it plays remains to be determined. Mice lacking TIMP3 have increased apoptosis in the involuting mammary gland ${ }^{35}$; however, overexpression of TIMP3 in various cell lines also leads to enhanced apoptosis, apparently via a Fasassociated pathway. ${ }^{33,34,36}$ TIMP3 is likely not affecting neutrophil apoptosis directly, however, because we found no differences in cell death between wild-type and Timp $3^{-1-}$ cells in response to staurosporine or TNF $\alpha$.

One possible mechanism by which TIMP3 could regulate neutrophil recruitment is proteolytic modification of chemokines. Many studies have demonstrated that MMPs are capable of processing chemokines and that this cleavage by MMPs can either enhance or inhibit the activity of the chemokine. ${ }^{2}$ For example, cleavage of LPS inducible CXC chemokine (LIX/CXCL5) by MMP1, 2, 8, 9, or 13 leads to increased activity and inflammatory cell recruitment. ${ }^{37,38}$ Although we did not detect differences in the level of neutrophil chemokines, the increased MMP activity in the lungs of Timp3 ${ }^{-1-}$ mice may lead to enhanced chemokine processing.

In conclusion, we have demonstrated that TIMP3 is crucial for the proper resolution of inflammation in the lung following injury. The mechanism by which TIMP3 regulates neutrophil chemotaxis remains to be determined; however, the reduced abundance of IL10 and IL13, potent anti-inflammatory cytokines, ${ }^{39}$ support the idea that TIMP3 may have a role in regulating the shift from a proinflammatory to anti-inflammatory environment following lung injury. Future studies will attempt to elucidate the mechanism through which TIMP3 regulates inflammation in the lung following injury focusing on identification of the specific metalloproteinases regulated by TIMP3.

\section{Acknowledgments}

We thank Drs. Timothy Birkland, Sean Kassim, and Charles Frevert for technical and analytical assistance.

\section{References}

1. Wheeler AP, Bernard GR: Acute lung injury and the acute respiratory distress syndrome: a clinical review. Lancet 2007, 369:1553-1564

2. Gill SE, Parks WC: Metalloproteinases and their inhibitors: regulators of wound healing. Int J Biochem Cell Biol 2008, 40:1334-1347

3. Baker AH, Edwards DR, Murphy G: Metalloproteinase inhibitors: biological actions and therapeutic opportunities. J Cell Sci 2002 , 115:3719-3727

4. Parks WC, Wilson CL, Lopez-Boado YS: Matrix metalloproteinases as modulators of inflammation and innate immunity. Nat Rev Immunol 2004, 4:617-629

5. Leco KJ, Waterhouse P, Sanchez OH, Gowing KL, Poole AR, Wakeham A, Mak TW, Khokha R: Spontaneous air space enlargement in the lungs of mice lacking tissue inhibitor of metalloproteinases-3 (TIMP-3). J Clin Invest 2001, 108:817-829

6. Mohammed FF, Smookler DS, Taylor SE, Fingleton B, Kassiri Z, Sanchez $\mathrm{OH}$, English JL, Matrisian LM, Au B, Yeh WC, Khokha R: Abnormal TNF activity in Timp3 ${ }^{-1-}$ mice leads to chronic hepatic inflammation and failure of liver regeneration. Nat Genet 2004, 36:969-977

7. Smookler DS, Mohammed FF, Kassiri Z, Duncan GS, Mak TW, Khokha R: Tissue inhibitor of metalloproteinase 3 regulates TNFdependent systemic inflammation. J Immunol 2006, 176:721-725

8. Zuo F, Kaminski N, Eugui E, Allard J, Yakhini Z, Ben-Dor A, Lollini L, Morris D, Kim Y, DeLustro B, Sheppard D, Pardo A, Selman M, Heller RA: Gene expression analysis reveals matrilysin as a key regulator of pulmonary fibrosis in mice and humans. Proc Natl Acad Sci USA 2002;99:6292-6297

9. Li Q, Park PW, Wilson CL, Parks WC: Matrilysin shedding of syndecan-1 regulates chemokine mobilization and transepithelial efflux of neutrophils in acute lung injury. Cell 2002, 111:635-646

10. Chen P, McGuire JK, Hackman RC, Kim KH, Black RA, Poindexter K, Yan W, Liu P, Chen AJ, Parks WC, Madtes DK: Tissue inhibitor of metalloproteinase-1 moderates airway re-epithelialization by regulating matrilysin activity. Am J Pathol 2008, 172:1256-1270

11. Kim KH, Burkhart K, Chen P, Frevert CW, Randolph-Habecker J, Hackman RC, Soloway PD, Madtes DK: Tissue inhibitor of metalloproteinase-1 deficiency amplifies acute lung injury in bleomycinexposed mice. Am J Respir Cell Mol Biol 2005, 33:271-279

12. Fattman CL, Gambelli F, Hoyle G, Pitt BR, Ortiz LA: Epithelial expression of TIMP-1 does not alter sensitivity to bleomycin-induced lung injury in C57BL/6 mice. Am J Physiol Lung Cell Mol Physiol 2008, 294:L572-L581

13. Pottier N, Chupin C, Defamie V, Cardinaud B, Sutherland R, Rios G, Gauthier F, Wolters PJ, Berthiaume Y, Barbry P, Mari B: Relationships between early inflammatory response to bleomycin and sensitivity to lung fibrosis: a role for dipeptidyl-peptidase I and tissue inhibitor of metalloproteinase-3? Am J Respir Crit Care Med 2007, 176:1098-1107

14. Boxio R, Bossenmeyer-Pourie C, Steinckwich N, Dournon C, Nusse $\mathrm{O}$ : Mouse bone marrow contains large numbers of functionally competent neutrophils. J Leukoc Biol 2004, 75:604-611

15. Frevert CW, Wong VA, Goodman RB, Goodwin R, Martin TR: Rapid fluorescence-based measurement of neutrophil migration in vitro. $\mathrm{J}$ Immunol Methods 1998, 213:41-52

16. Yu WH, Yu S, Meng Q, Brew K, Woessner JF Jr: TIMP-3 binds to sulfated glycosaminoglycans of the extracellular matrix. J Biol Chem 2000, 275:31226-31232

17. Garcia-Alvarez J, Ramirez R, Checa M, Nuttall RK, Sampieri CL, Edwards DR, Selman M, Pardo A: Tissue inhibitor of metalloproteinase-3 is up-regulated by transforming growth factor- $\beta 1$ in vitro and expressed in fibroblastic foci in vivo in idiopathic pulmonary fibrosis. Exp Lung Res 2006, 32:201-214 
18. Greenlee KJ, Werb Z, Kheradmand F: Matrix metalloproteinases in lung: multiple, multifarious, and multifaceted. Physiol Rev 2007, 87:69-98

19. Matute-Bello G, Wurfel MM, Lee JS, Park DR, Frevert CW, Madtes DK, Shapiro SD, Martin TR: Essential role of MMP-12 in Fas-induced lung fibrosis. Am J Respir Cell Mol Biol 2007, 37:210-221

20. Corbel M, Caulet-Maugendre S, Germain N, Molet S, Lagente V, Boichot $\mathrm{E}$ : Inhibition of bleomycin-induced pulmonary fibrosis in mice by the matrix metalloproteinase inhibitor batimastat. J Pathol 2001, 193:538-545

21. Betsuyaku T, Fukuda Y, Parks WC, Shipley JM, Senior RM: Gelatinase $B$ is required for alveolar bronchiolization after intratracheal bleomycin. Am J Pathol 2000, 157:525-535

22. Black RA, Rauch CT, Kozlosky CJ, Peschon JJ, Slack JL, Wolfson MF, Castner BJ, Stocking KL, Reddy P, Srinivasan S, Nelson N, Boiani N, Schooley KA, Gerhart M, Davis R, Fitzner JN, Johnson RS, Paxton RJ, March CJ, Cerretti DP: A metalloproteinase disintegrin that releases tumour-necrosis factor- $\alpha$ from cells. Nature 1997, 385:729-733

23. Ryu J, Vicencio AG, Yeager ME, Kashgarian M, Haddad GG, Eickelberg $O$ : Differential expression of matrix metalloproteinases and their inhibitors in human and mouse lung development. Thromb Haemost 2005, 94:175-183

24. Leco KJ, Khokha R, Pavloff N, Hawkes SP, Edwards DR: Tissue inhibitor of metalloproteinases-3 (TIMP-3) is an extracellular matrixassociated protein with a distinctive pattern of expression in mouse cells and tissues. J Biol Chem 1994, 269:9352-9360

25. Mukhopadhyay S, Hoidal JR, Mukherjee TK: Role of TNF $\alpha$ in pulmonary pathophysiology. Respir Res 2006, 7:125

26. Manoury B, Caulet-Maugendre S, Guenon I, Lagente V, Boichot E: TIMP-1 is a key factor of fibrogenic response to bleomycin in mouse lung. Int J Immunopathol Pharmacol 2006, 19:471-487

27. Swiderski RE, Dencoff JE, Floerchinger CS, Shapiro SD, Hunninghake GW: Differential expression of extracellular matrix remodeling genes in a murine model of bleomycin-induced pulmonary fibrosis. Am J Pathol 1998, 152:821-828

28. Madtes DK, Elston AL, Kaback LA, Clark JG: Selective induction of tissue inhibitor of metalloproteinase-1 in bleomycin-induced pulmonary fibrosis. Am J Respir Cell Mol Biol 2001, 24:599-607
29. Brew K, Dinakarpandian D, Nagase $H$ : Tissue inhibitors of metalloproteinases: evolution, structure and function. Biochim Biophys Acta 2000, 1477:267-283

30. Gill SE, Pape MC, Khokha R, Watson AJ, Leco KJ: A null mutation for tissue inhibitor of metalloproteinases-3 (Timp-3) impairs murine bronchiole branching morphogenesis. Dev Biol 2003, 261:313-323

31. Martin EL, Moyer BZ, Pape MC, Starcher B, Leco KJ, Veldhuizen RA: Negative impact of tissue inhibitor of metalloproteinase-3 null mutation on lung structure and function in response to sepsis. Am J Physiol Lung Cell Mol Physiol 2003, 285:L1222-L1232

32. Martin EL, Sheikh TA, Leco KJ, Lewis JF, Veldhuizen RA: Contribution of alveolar macrophages to the response of the TIMP3 null lung during a septic insult. Am J Physiol Lung Cell Mol Physiol 2007, 293:L779-L789

33. Bond M, Murphy G, Bennett MR, Amour A, Knauper V, Newby AC, Baker AH: Localization of the death domain of tissue inhibitor of metalloproteinase-3 to the $\mathrm{N}$ terminus: metalloproteinase inhibition is associated with proapoptotic activity. J Biol Chem 2000, 275:41358-41363

34. Smith MR, Kung H, Durum SK, Colburn NH, Sun Y: TIMP-3 induces cell death by stabilizing TNF- $\alpha$ receptors on the surface of human colon carcinoma cells. Cytokine 1997, 9:770-780

35. Fata JE, Leco KJ, Voura EB, Yu HY, Waterhouse P, Murphy G, Moorehead RA, Khokha R: Accelerated apoptosis in the Timp-3deficient mammary gland. J Clin Invest 2001, 108:831-841

36. Bond M, Murphy G, Bennett MR, Newby AC, Baker AH: Tissue inhibitor of metalloproteinase-3 induces a Fas-associated death domain-dependent type II apoptotic pathway. J Biol Chem 2002, 277:13787-13795

37. Tester AM, Cox JH, Connor AR, Starr AE, Dean RA, Puente XS, Lopez-Otin C, Overall CM: LPS responsiveness and neutrophil chemotaxis in vivo require PMN MMP-8 activity. PLoS One 2007, 2:e312

38. Van Den Steen PE, Wuyts A, Husson SJ, Proost P, Van Damme J, Opdenakker G: Gelatinase B/MMP-9 and neutrophil collagenase/ MMP-8 process the chemokines human GCP-2/CXCL6, ENA-78/ CXCL5 and mouse GCP-2/LIX and modulate their physiological activities. Eur J Biochem 2003, 270:3739-3749

39. Hanada T, Yoshimura A: Regulation of cytokine signaling and inflammation. Cytokine Growth Factor Rev 2002, 13:413-421 